\title{
A pesquisa em educação em ciências e a formação de professores
}

Nos últimos vinte anos a temática da formação de professores vem se consolidando como uma das mais presentes nos trabalhos de pesquisa em educação em ciências. Ao longo desse processo, tem sido comum que esses estudos busquem parte de sua fundamentação teórica em obras já clássicas (por exemplo, GAUTHIER et al., 1998; GIROUX, 1997; MARCELO GARCÍA, 1999; SCHÖN, 2000; TARDIF, 2004). As referidas obras gradativamente originaram um corpo de conhecimentos e proposições que contribuíram para novos patamares de debate, demonstrando, por exemplo, a inadequação da concepção da racionalidade técnica, e a pluralidade dos saberes docentes. Ao mesmo tempo, pesquisas voltadas à obtenção e à discussão de dados de natureza empírica avançaram de modo significativo ao disponibilizarem numerosas análises a respeito de concepções de professores e a respeito de programas e atividades de formação inicial e formação em serviço.

Tendo em vista esse cenário, muitos aspectos poderiam ser levantados e discutidos. Selecionarei para o momento, por sua relevância e complexidade, um único aspecto apenas, que é o diálogo entre os aportes da pesquisa acadêmica e os processos formativos que se dão no âmbito das escolas de educação básica e no âmbito das universidades. Em relação a tal problemática, algumas perguntas podem ser feitas: Qual tem sido - e qual deveria ser idealmente - o papel da produção acadêmica (em ensino) no âmbito do processo de formação de professores e, principalmente, no âmbito de seu trabalho? Até que ponto a produção acadêmica em ensino tem real potencial de se transformar em uma contribuição para o trabalho dos professores da educação básica, e quais os caminhos para que esses professores considerem os conhecimentos elaborados pela academia, avaliem-nos e os transformem em favor de sua prática? Que tipo de saberes os professores estruturam a partir do contato com a produção acadêmica em ensino, e como esses saberes dialogam com outros saberes docentes, em função dos desafios do trabalho educativo? Há diversas respostas para essas questões, e colocarei aqui apenas algumas sugestões de apontamentos gerais. Não seguirei uma ordem linear para tal reflexão, já que os diferentes elementos do problema aparecem imbricados.

Os conhecimentos produzidos pela academia, e que podem ser úteis para as discussões sobre ensino, distribuem-se em campos de estudo diversos, embora inter-relacionados. História da Educação, Políticas Públicas em Educação, Filosofia da Educação, Psicologia da Educação, Didática, Metodologia do Ensino e Linguagem são exemplos desses campos. Há porém, nos meios escolares e até na academia, certa desconfiança quanto à pertinência e o valor 
desse conjunto heterogêneo de conhecimentos (GAUTHIER et al., 1998; PIMENTA, 2005; TARDIF, 2004). Entre os professores da educação básica, é comum a ideia de que os conhecimentos acadêmicos sobre ensino devam ser prescritivos; no entanto, como essa expectativa geralmente não se cumpre, sobrevém a ideia de que 'a teoria não tem nenhuma relação com a prática', e 'só a prática' é capaz de formar o professor. Em alguns casos se argumenta que a escola e a universidade são instituições movidas por objetivos diferentes, daí o 'descompasso' entre o trabalho desenvolvido pelos pesquisadores universitários e as necessidades do ensino escolar, sendo importante que ambas as partes se engajem em esforços comuns de elaboração de conhecimentos. Por sua vez, Gauthier et al. (1998) entendem que os saberes mais relevantes para a formação docente são aqueles que informam sobre os elementos eficazes da prática real e corriqueira dos professores; esses saberes seriam elaborados através de numerosos trabalhos de pesquisa acadêmica que identificariam e validariam uma série de procedimentos empregados pelos professores nas salas de aula normais, originando assim um acervo de "saberes da ação pedagógica"; assim, tal concepção é reticente ou pouco otimista em relação aos conhecimentos acadêmicos clássicos ("saberes das ciências da educação").

Não obstante a parcela de razão que encontremos nesses argumentos, é preciso que algumas ponderações sejam feitas, a fim de que não se desqualifique a pesquisa universitária, isto é, não se a entenda como algo próximo ao diletantismo: (a) o modo específico pelo qual a investigação acadêmica em educação e ensino contribui é através da produção de literatura e ou da inserção de professores da escola básica nas equipes de pesquisadores; portanto, não há de se querer que essa investigação seja uma fonte de saberes do tipo 'experiencial'; (b) em virtude de sua própria razão ser, a pesquisa acadêmica está voltada, direta ou indiretamente, para a constituição de teoria; a teoria, por sua vez, é necessariamente composta de enunciados de caráter geral ou abstrato; disso resulta que também não faz sentido achar que a pesquisa acadêmica deva pronunciar-se sobre os inúmeros contextos específicos em que os professores atuam; (c) como os enunciados componentes da teoria são de caráter geral, é esperado que deem margem a proposições específicas não enquanto se encontrem em sua forma original, e sim no momento em que forem traduzidos em direção às situações concretas com as quais o professor se defronta; por exemplo, sabe-se que o ensino por investigação propõe o estudo de problemas abertos que possam ser de interesse dos estudantes (CARVALHO, 2013), porém, esses problemas só podem ser definidos em função do nível escolar pretendido, do conteúdo a ser abordado, das características das turmas de alunos, dos objetivos a serem atingidos, dos saberes e da criatividade dos professores etc.; trata-se pois de compreender que a teoria requer a ação do professor (no sentido de explorá-la, traduzi-la, avaliá-la, transformá-la) para que assim ganhe vida; (d) não há prática sem teoria ou teoria sem prática (FREIRE, 2014; SÁNCHEZ VÁZQUEZ, 2007; TARDIF, 2004); dito de outro modo, não cabe entender a pesquisa universitária com uma atividade 'alheia à prática', inclusive porque é comum que ela investigue componentes integrantes de situaçôes educativas reais; o que me parece necessário, nesse caso, é que se construa maior diálogo entres a proposições da pesquisa universitária e as ideias dos professores da educação básica; (e) a relação teoria-prática no trabalho do professor não pode mais ser entendida segundo a concepção da racionalidade técnica, tornando-se necessário que seja pensada em termos de conceitos como os de práxis e racionalidade crítica ou discursiva (FREIRE, 2014; GIROUX, 1997; SÁNCHEZ VÁZQUEZ, 2007); nesse sentido, o papel da produção acadêmica em ensino passa a ser o de oferecer contributos para a reflexão sobre a prática e sobre o contexto geral em que se dá ação educativa, contributos estes que podem ser distribuídos em três eixos principais, o crítico (que se refere à crítica do ensino habitual e de seus condicionantes), o propositivo (ligado à elaboração de novas ideias e propostas para o ensino 
escolar) e o reiterativo (que se refere à produção de saberes “da ação pedagógica", conforme a descrição de Gauthier et al. (1998).

Questionamentos dessa natureza conduzem a uma reflexão sobre os desafios referentes a colocar os conhecimentos produzidos pela pesquisa acadêmica em ensino em diálogo efetivo com os saberes docentes dos estudantes de licenciatura e dos professores em serviço. Trata-se de desafios de grande monta, que, por sua complexidade e renovação ao longo do tempo, vão requerer os esforços de pesquisadores universitários e professores da educação básica indefinidamente. Também nesse campo, muitos avanços vêm sendo obtidos. No entanto, atenção mais detalhada precisa ser dada às condições, abordagens e estratégias da formação de professores. Compreender melhor, por exemplo, como as políticas públicas influenciam as condições da formação inicial e continuada, e que modificações de cenários deveriam ser feitas, a fim de impulsionar o desenvolvimento profissional dos professores - se é que haja interesse nesse sentido por parte dos gestores públicos.

Nardi et al. (2009) entrevistaram professores de ciências que atuaram nas últimas décadas em escolas de educação básica do Estado de São Paulo, a respeito de "procedimentos e resultados de pesquisa na área e suas possíveis implicações para o ensino". Grande parte dos entrevistados apontou como um problema a inadequação das políticas públicas, conforme explicitado no excerto abaixo.

É possível de perceber na tônica de suas falas a existência de forte crítica a políticas públicas implantadas nas últimas décadas pelos governos, que consideram responsáveis pela deterioração da qualidade do ensino. Destacase particularmente a chamada "progressão continuada", na qual a escola tem de gerar mecanismos para que o aluno seja recuperado, evitando a repetência [...]. (NARDI et al., 2009, p. 8).

Outra temática que merece atenção mais detalhada é aquela que diz respeito às abordagens e estratégias empregadas nos programas de formação inicial e de formação continuada. Interessa saber quais são essas abordagens e estratégias, e como o público alvo (licenciandos e professores em serviço) interage com elas. Especificamente, cabe perguntar - para resgatar o aspecto levantado no início desse breve comentário - de que maneira os programas de formação trabalham com a 'teoria' (produção acadêmica em educação e ensino), e como esses dados contribuem para a reflexão sobre os processos de formação docente. Pesquisas que investissem nessa linha tenderiam a ultrapassar a exterioridade dos fenômenos, e adentrar os mecanismos de funcionamento deles.

Fernando Bastos

Universidade Estadual Paulista (Unesp), Faculdade de Ciências, Departamento de Educação, Bauru, SP, Brasil. E-mail: <ferbastos@fc.unesp.br>. 


\section{Referências}

CARVALHO, A. M. P. (Org.). Ensino de ciências por investigação: condições para implementação em sala de aula. São Paulo: Cengage Learning, 2013.

FREIRE, P. Pedagogia do oprimido. 57. ed. Rio de Janeiro: Paz e Terra, 2014.

GAUTHIER, C. et al. Por uma teoria da pedagogia: pesquisas contemporâneas sobre o saber docente. Ijuí: Editora Unijuí, 1998.

GIROUX, H. A. Os professores como intelectuais: rumo a uma pedagogia crítica da aprendizagem. Porto Alegre: Artes Médicas, 1997.

MARCELO GARCÍA, C. Formação de professores: para uma mudança educativa. Porto: Porto Editora, 1999.

NARDI, R. et al. A pesquisa em ensino de física e o ensino de sala de aula: memórias de professores que atuaram nas últimas décadas. In: INTER-AMERICAN CONFERENCE ON PHYSICS EDUCATION, 10., 2009, Medellín. Actas... Medellín: Universidad de Antioquia, 2009.

PIMENTA, S. G. (Org.). Saberes pedagógicos e atividade docente. 4. ed. São Paulo: Cortez, 2005.

SÁNCHEZ VÁZQUEZ, A. Filosofia da práxis. Buenos Aires: CLACSO; São Paulo: Expressão Popular, 2007.

SCHÖN, D. A. Educando o profissional reflexivo: um novo design para o ensino e a aprendizagem. Porto Alegre: Artmed, 2000.

TARDIF, M. Saberes docentes e formação profissional. 4. ed. Petrópolis: Vozes, 2004. 